\title{
Temporal- and hormone-dependent changes in uterine sensitization for the decidual cell reaction and decidualization in vitro of rat endometrial stromal cells
}

\author{
T. G. Kennedy and H. E. Ross \\ Departments of Physiology and Obstetrics and Gynaecology. The University of Western Ontario, London, \\ Ontario N6A 5C1, Canada
}

\begin{abstract}
The ability of endometrial stromal cells from nonsensitized rat uteri to undergo decidualization in vitro was investigated. Cells were obtained by enzymatic dispersion from uteri of ovariectomized, steroid-treated rats at the equivalent of day 4,5 or 6 of pseudopregnancy, or on day 5 from rats treated with $0,0.3$ or $1.0 \mu \mathrm{g}$ oestradiol (low, intermediate or high doses of oestradiol, respectively) on day 4 , and cultured for 24,48 or $72 \mathrm{~h}$. Decidualization in vivo, as assessed by uterine mass 5 days after the unilateral intrauterine injection of $100 \mu \mathrm{l}$ sesame oil, was maximal for rats receiving the deciduogenic stimulus on day 5 and treated with the intermediate dose of oestradiol. Under control conditions in vitro, alkaline phosphatase (ALP) activity, the increase in ALP activity with time, and prostaglandin $E_{2}$ $\left(\mathrm{PGE}_{2}\right)$ accumulation in the medium were greatest for cells from maximally sensitized uteri. Indomethacin, an inhibitor of $\mathrm{PG}$ synthesis, reduced $\mathrm{PGE}_{2}$ accumulation to barely detectable amounts, and decreased ALP activity, especially in cells from maximally sensitized uteri, indicating that endogenous PG production contributed to the increase in ALP activity in these cells. The addition of $\mathrm{PGE}_{2}$ with indomethacin increased ALP activities. However, ALP activities were lower for cells derived from nonsensitized uteri when compared with cells from maximally sensitized uteri. These results suggest that endometrial stromal cells from nonsensitized uteri have a reduced capacity to undergo decidualization in vitro, and that this reduced capacity is not explained by differences in $\mathrm{PGE}_{2}$ production.
\end{abstract}

\section{Introduction}

In rodents, the differentiation of endometrial stromal cells to decidual cells occurs in vivo in response to either blastocysts or artificial stimuli (Psychoyos, 1973). Decidualization in response to an artificial stimulus can be obtained only during a limited period in pregnancy, pseudopregnancy, or when the uterus has been prepared by an appropriate regimen of hormone treatments (Psychoyos, 1973; Finn and Porter, 1975; Kennedy, 1980a). In addition, oestrogen in low, but not high, doses acts synergistically with progesterone to sensitize the rat and mouse uterus (Yochim and De Feo, 1963; Armstrong and King, 1971; Finn and Porter, 1975; Sartor et al., 1978; Kennedy, 1980b). Thus, uterine sensitization for the decidual cell reaction in vivo is time- and hormone-dependent.

Endometrial stromal cells isolated from sensitized rat uteri undergo decidualization when cultured as indicated by morphology (Vladimirsky et al., 1977; Sananès et al., 1978), expression of desmin (Glasser and Julian, 1986; Mani et al., 1992) and laminin (Mani et al., 1992), and changes in ALP activity (Yee and Kennedy, 1991, 1993). However, decidualization in vitro differs from that which occurs in vivo because

Received 17 May 1996. whereas the latter requires progesterone (Psychoyos, 1973) the former is apparently independent of this hormone (Sananès et al, 1980).

The influence of uterine sensitization on subsequent decidualization in vitro has not been investigated in detail. On the basis of the expression of desmin and laminin, Mani $e t$ al. (1992) concluded that decidualization in vitro was independent of uterine sensitization. However, that study was qualitative rather than quantitative. The present study was undertaken to determine whether the state of uterine sensitization at the time that the endometrial stromal cells were isolated affected the extent of decidualization in vitro. Decidualization was assessed by determining ALP activity (Yee and Kennedy, 1991, 1993). Because PGs, particularly of the E-series, mediate, at least in part, decidualization of endometrial stromal cells in vivo and in vitro (Kennedy, 1994), the effect of manipulating PG concentrations during the culture period was determined. The contribution of endogenous PG production to decidualization in vitro was assessed by inhibiting its production with indomethacin (Vane, 1971). Because differences in decidualization in vitro might be a consequence of differences in the abilities of the cells to produce PGs, the effect of the addition of $\mathrm{PGE}_{2}$ to the culture medium with indomethacin was determined. 


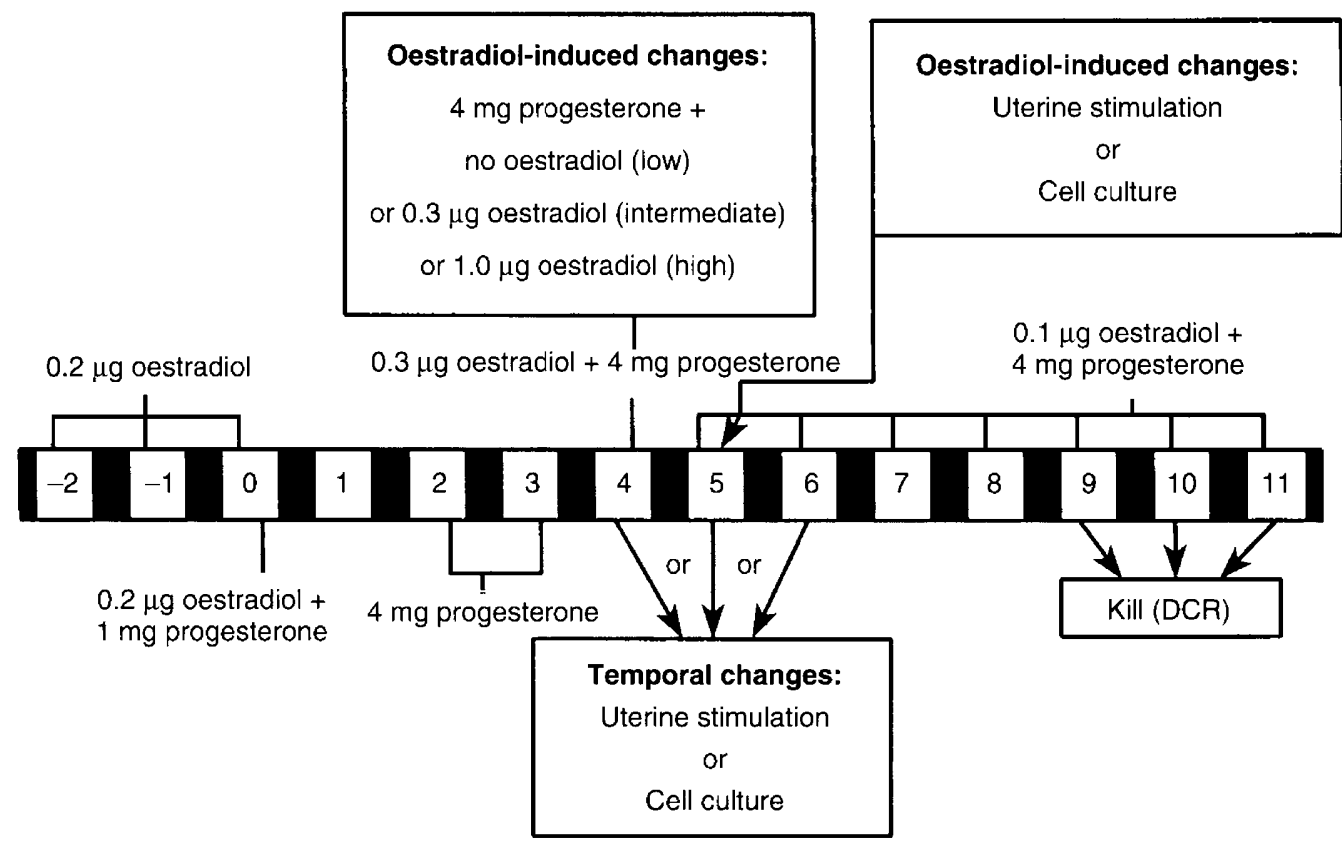

Fig. 1. Schematic representation of the treatment protocols administered to ovariectomized rats to obtain uteri differentially sensitized for the decidual cell reaction (DCR). ( $\boldsymbol{\square}$ ) periods when the lights were off, ( $\square$ ) when the lights were on. Numbers give the equivalent day of pseudopregnancy. Temporal-dependent changes were investigated by giving rats a deciduogenic stimulus on day 4, day 5, or day 6 and they were killed 5 days later to assess the DCR, or killed on day 4, 5, or 6 to obtain endometrial stromal cells for culture. Except for those killed on day 4 , all rats received $0.3 \mu \mathrm{g}$ oestradiol plus $4 \mathrm{mg}$ progesterone on the afternoon of day 4 . Oestradiol-dependent changes were investigated by treating with no oestradiol (low), $0.3 \mu \mathrm{g}$ oestradiol (intermediate), or $1.0 \mu \mathrm{g}$ oestradiol (high) on the afternoon of day 4; they were given a deciduogenic stimulus on day 5 and killed 5 days later to assess the DCR, or killed on day 5 to obtain endometrial stromal cells for culture. Note that the protocols for the day 5 rats and those treated with the intermediate dose of oestradiol were identical.

\section{Materials and Methods}

\section{Animals}

Female Sprague-Dawley rats were obtained from Harlan Sprague-Dawley Inc., Indianapolis, IN at $200-225 \mathrm{~g}$ body mass and housed in temperature- and light-controlled conditions (lights on from 05:00-19:00 h) with free access to food and water.

\section{Treatment of animals}

The rats were ovariectomized under ether anaesthesia and allowed at least 5 days to recover from the surgery. To obtain uteri differentially sensitized for the decidual cell reaction, rats were given oestradiol and progesterone subcutaneously in sesame oil according to the protocols illustrated (Fig. 1). To investigate the effects of temporal changes in uterine sensitization on subsequent decidualization in vitro of isolated endometrial stromal cells, the same sequence of oestradiol and progesterone was administered to all rats, but animals were killed on the morning of the equivalent of day 4 , day 5 or day 6 of pseudopregnancy. (Day 1 is the last day of vaginal cornification.) In these experiments, the initiation of hormone treatments was staggered so that all animals in an experiment were killed on the same day. To investigate the effects of oestradiol-induced changes in uterine sensitization on subsequent decidualization in vitro, different amounts of oestradiol $(0,0.3$ or $1.0 \mu \mathrm{g})$ with a constant amount of progesterone $(4 \mathrm{mg}$ ) were given on the afternoon of the equivalent of day 4 of pseudopregnancy, and the animals were killed on the morning of the next day. At all times other than day 4 , the rats received the same steroid treatments. For brevity, these treatments will be referred to as low, intermediate or high doses of oestradiol, respectively.

\section{Decidualization in vivo}

An experiment was conducted to confirm that the treatment protocols (Fig. 1) resulted in uteri which were differentially sensitized for the decidual cell reaction. Five groups of rats, at the equivalent of day 4,5 or 6 of pseudopregnancy, or receiving low, intermediate (same animals as day 5) or high doses of oestradiol, received a deciduogenic stimulus, the unilateral intrauterine injection of $100 \mu \mathrm{l}$ sesame oil (Finn and Keen, 1963). The intrauterine injections were given into the uterotubal end of the uterine horns under ether anaesthesia between 10:30 and 12:00 $\mathrm{h}$ on the appropriate day. The rats were treated daily with oestradiol and progesterone as shown in Fig. I and killed 5 days after the deciduogenic stimulus. As an indicator of decidualization, the mass of the stimulated and 
nonstimulated uterine horns was determined (De Feo, 1963; Finn and Keen, 1963).

\section{Endometrial stromal cell isolation and culture}

Endometrial stromal cells were isolated from the differentially sensitized uteri by the method of McCormack and Glasser (1980) as modified by Yee and Kennedy (1991). In summary, uterine horns, split longitudinally, were initially incubated in pancreatin (GIBCO-BRL, Burlington, Ontario) and dispase II (Boehringer Mannheim, Laval, Quebec) to liberate epithelial cells, then in collagenase (type II, Sigma Chemical Company, St Louis, MO) to liberate endometrial stromal cells. The stromal cells were suspended in Dulbecco's modified Eagle's medium: F-12 nutrient mixture containing heatinactivated charcoal-stripped fetal calf serum $(10 \%)(\mathrm{v} / \mathrm{v})$, penicillin $\left(50 \mathrm{U} \mathrm{ml}^{-1}\right)$, streptomycin $\left(50 \mu \mathrm{g} \mathrm{ml} \mathrm{g}^{-1}\right)$ and fungizone $\left(1.25 \mu \mathrm{g} \mathrm{ml}^{-1}\right.$; all GIBCO-BRL). The cell suspension was filtered through nylon mesh $(70 \mu \mathrm{m})$ to remove contaminating glands, and plated at $5 \times 10^{5}$ cells in $0.5 \mathrm{ml}$ medium in 24-well plates (Becton-Dickinson, Lincoln Park, NJ). After an initial incubation period of $2 \mathrm{~h}$ at $37^{\circ} \mathrm{C}$ under $5 \% \mathrm{CO}_{2}: 95 \%$ air to allow differential attachment of stromal cells, the medium was removed and replaced with fresh medium containing the treatments.

The stromal cells were cultured for up to $72 \mathrm{~h}$ with indomethacin $\left(10^{-5} \mathrm{~mol} \mathrm{l}^{-1}\right.$; Sigma) or with indomethacin plus $\mathrm{PGE}_{2}\left(1 \mu \mathrm{g} \mathrm{ml}^{-1}\right.$; Cayman Chemical Company, Ann Arbor, MI). The treatments were added to the culture medium in ethanol, the final concentration of which did not exceed $1 \%$ $(\mathrm{v} / \mathrm{v})$. Cells not receiving a treatment were cultured with the same concentration of ethanol. The culture medium was replaced every $24 \mathrm{~h}$ and stored at $-20^{\circ} \mathrm{C}$ until assayed.

\section{Alkaline phosphatase activity and protein content}

After 24,48 or $72 \mathrm{~h}$ of culture, the medium was removed from some wells and the cells washed with Dulbecco's PBS (GIBCO-BRL). The cells in some of the wells were lysed with $0.25 \%(\mathrm{w} / \mathrm{v})$ sodium deoxycholate, $\mathrm{pH} 9.5$, and stored at $-70^{\circ} \mathrm{C}$ until assayed for ALP activity (Lowry, 1957), which is expressed as nmol of the substrate, $p$-nitrophenol phosphate (Sigma) hydrolysed per $30 \mathrm{~min}$. The protein content of some wells was determined by the method of Lowry et al. (1951) after the cells had been solubilized in $1 \%(\mathrm{w} / \mathrm{v})$ SDS- $10^{-3} \mathrm{~mol}$ EDTA $\mathrm{l}^{-1}$ and stored at $-70^{\circ} \mathrm{C}$. Bovine serum albumin (Sigma) was used as the standard.

\section{Prostaglandin $E_{2}$ radioimmunoassay}

The collected culture medium was acidified to $\mathrm{pH} 3.0-3.5$ with $1 \mathrm{~mol} \mathrm{HCI} \mathrm{l}^{-1}$ and extracted twice with 4 volumes of diethyl ether to determine the accumulation of $\mathrm{PGE}_{2}$ in the medium when cells were cultured under control conditions or in the presence of indomethacin. The organic phase was recovered, pooled and evaporated to dryness under nitrogen. Samples were reconstituted in PBS containing gelatin $\left(10^{-1}\right.$ mol sodium phosphate $1^{-1}$ in $0.154 \mathrm{~mol}$ sodium chloride $\mathrm{I}^{-1}, 0.1 \%(\mathrm{w} / \mathrm{v})$ gelatin, $\left.\mathrm{pH} 6.8\right)$ and then used in a

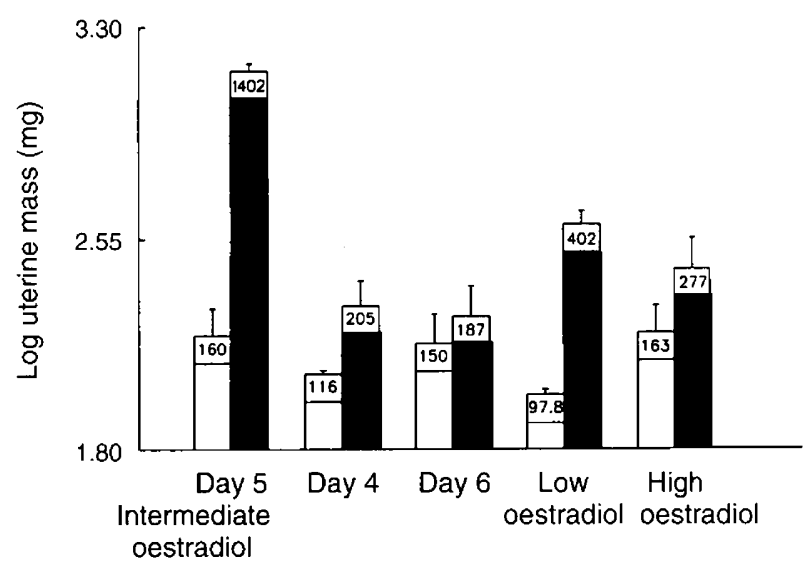

Fig. 2. Effects of the unilateral intrauterine injection of $100 \mu \mathrm{l}$ sesame oil on mass of uterine horns after 5 days for rats receiving the treatment protocols presented in Fig. 1. Each bar represents the mean \pm SEM of the log-transformed data of $7-8$ rats. The geometric mean is given at the top of each bar.

radioimmunoassay specific for $\mathrm{PGE}_{2}$, as described by Kennedy (1979). The sensitivity of the assay was approximately $10 \mathrm{pg}$ per tube; the intra- and interassay coefficients of variation were approximately $6 \%$ and $10 \%$, respectively.

\section{Statistical analyses}

Uterine mass was log-transformed and analysed by analysis of variance; the variation was partitioned on a within- and between-animal basis. Because a significant interaction was present, Duncan's new multiple range test (Steel and Torrie, 1960) was used for subsequent between-group comparisons.

Data from the cell cultures are presented as means \pm SEM of triplicate or quadruplicate observations from a single experiment. Each experiment was performed at least three times with different endometrial stromal cell preparations (6-8 rats per preparation). Because of significant differences between experiments, as determined by analysis of variance, the data from different experiments have not been pooled. Comparison of experiments indicated that the treatment effects were qualitatively, although not always quantitatively, consistent. The $\mathrm{PGE}_{2}$ data were log-transformed before analysis to remove heterogeneity of variance (Snedecor, 1956). Treatment effects were determined by analysis of variance; when significant interactions were found, Duncan's new multiple range tests (Steel and Torrie, 1960) were used for group comparisons.

\section{Results}

\section{Decidualization in vivo}

Uterine mass 5 days after the unilateral application of a deciduogenic stimulus to groups of rats treated with the different protocols is presented (Fig. 2). Mixed-model analysis of variance of the log-transformed mass revealed a significant $(P<0.001)$ interaction between the effects of deciduogenic stimulation and protocol. The mass of the nonstimulated uterine horns did not differ significantly $(P>0.05)$ between 

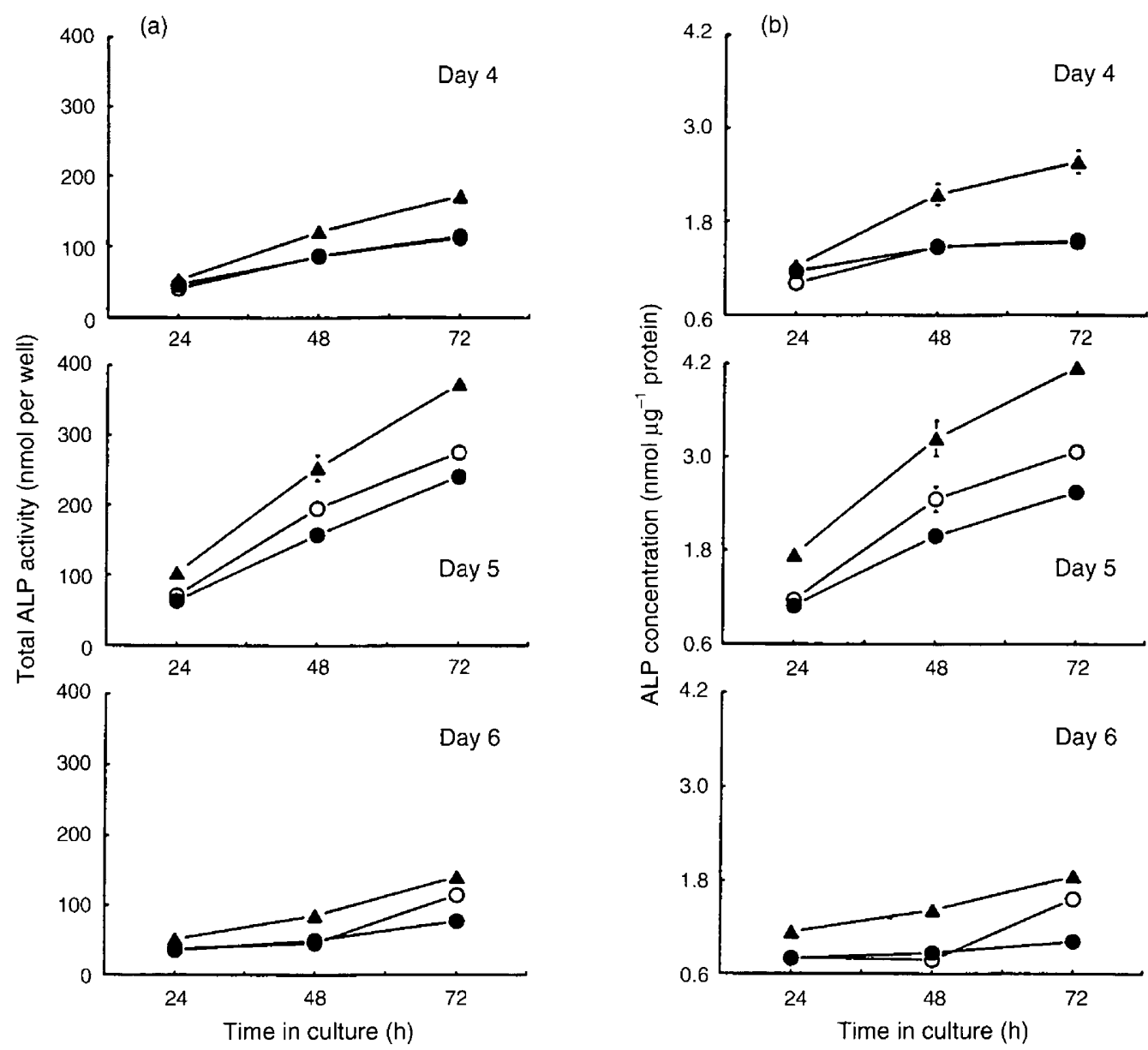

Fig. 3. Total alkaline phosphatase (ALP) activity (a) and ALP concentration (b) in endometrial stromal cells obtained from uteri at the equivalent of day 4,5 or 6 of pseudopregnancy and cultured for 24,48 or $72 \mathrm{~h}$ under control $(O)$ conditions, with indomethacin $(-)\left(10^{-5} \mathrm{~mol} \mathrm{l}^{-1}\right)$, or with prostaglandin $\mathrm{E}_{2}(\mathbf{\Lambda})\left(\mathrm{PGE}_{2}\right.$; $1 \mu \mathrm{g} \mathrm{ml}^{-1}$ ) plus indomethacin. Each point represents the mean \pm SEM of 3-4 observations; where the SEM is not apparent, it is smaller than the symbol.

groups. By contrast, for the day 5 intermediate dose of oestradiol group, the mass of the stimulated horns was greater $(P<0.01)$ than in any other group. The group receiving the low dose of oestradiol had uterine mass of stimulated horns greater $(P<0.05)$ than those of the day 4 or day 6 group, but not different $(P>0.05)$ from that of the group receiving the high dose of oestradiol.

\section{Temporal changes in uterine sensitization and decidualization in vitro}

In a series of experiments, the effects of time in culture and of manipulation of $\mathrm{PGE}_{2}$ concentrations on total $\mathrm{ALP}$ activity and ALP activity per unit of protein (ALP concentration) were determined for endometrial stromal cells obtained from uteri at the equivalent of day 4,5 or 6 of pseudopregnancy. For total ALP activity (Fig. 3a), analysis of variance indicated a significant $(P<0.05)$ three-way interaction between the effects of day of pseudopregnancy, time in culture, and treatment during culture. For control cultures, total ALP activity increased significantly from $24 \mathrm{~h}$ to $72 \mathrm{~h}$ in culture, irrespective of the day of pseudopregnancy on which they were obtained. However, for cells obtained from day 5 of pseudopregnancy, total ALP activity was greatest at any given time, and the increase from $24 \mathrm{~h}$ to $72 \mathrm{~h}$ was also greatest.

When indomethacin was added to the culture medium, total ALP activity still increased significantly $(P<0.001)$ with time in culture. For cells obtained from uteri at day 4 or day 6 of pseudopregnancy, treatment with indomethacin had no significant effect when compared with the corresponding control, except for day 6 cells at $72 \mathrm{~h}$ when total activity was significantly $(P<0.01)$ decreased. By contrast, for day 5 cells, at 24,48 and $72 \mathrm{~h}$ of culture, indomethacin treatment resulted in significantly $(P<0.01)$ lower total ALP activity. At culture for 24,48 and $72 \mathrm{~h}$, AlP activity was always greatest for day 5 cells, and least for day 6 cells.

The addition of $\mathrm{PGE}_{2}$ with indomethacin resulted in total ALP activities that were significantly $(P<0.01)$ higher than in the same cells under control conditions or treated with indomethacin. Total ALP activity was greatest $(P<0.01)$ for cells obtained from day 5 uteri. At 48 and $72 \mathrm{~h}$ in culture, activity in day 4 cells was greater $(P<0.01)$ than in day 6 cells. 




Fig. 4. Accumulation of prostaglandin $E_{2}\left(P_{G E}\right)$ in the medium of endometrial stromal cells obtained from uteri at the equivalent of day $4(0), 5(\square)$ or $6(\triangle)$ of pseudopregnancy and cultured for 24,48 or $72 \mathrm{~h}$ under control conditions; the medium was replaced every $24 \mathrm{~h}$. Each point represents the mean \pm SEM of 3-4 observations; where the SEM is not apparent, it is smaller than the symbol.

Because changes in cellular protein could confound the effects of treatments, ALP concentration (activity per unit cellular protein) was also analysed (Fig. 3b). Analysis of variance revealed a significant $(P<0.05)$ three-way interaction between the effects of day of pseudopregnancy, time in culture, and treatment. For control cultures, ALP concentration increased significantly $(P<0.001)$ with time for all cells. However, ALP concentration and the increase in ALP concentration during culture were greatest $(P<0.01)$ for cells obtained from uteri at day 5 .

When the cells were cultured in the presence of indomethacin, ALP concentration increased $(P<0.001)$ with time. For day 4 and day 6 cells, indomethacin treatment had no significant effect when compared with the corresponding controls, except for day 6 cells at $72 \mathrm{~h}$ when the concentration was decreased $(P<0.01)$. By contrast, indomethacin treatment of day 5 celis decreased $(P<0.01)$ ALP concentrations at 48 and $72 \mathrm{~h}$. At 48 and $72 \mathrm{~h}$, ALP concentration was greatest for day 5 cells, and least for day 6 cells.

Treatment of the cells with $\mathrm{PGE}_{2}$ plus indomethacin resulted in ALP concentrations which, within each time and day, were greater than for controls or indomethacintreated cultures, except for day 4 cells at $24 \mathrm{~h}$. At 24,48 and $72 \mathrm{~h}$ in culture, ALP concentration was greatest for day 5 cells. At 48 and $72 \mathrm{~h}$ in culture, ALP concentration was greater $(P<0.01)$ in day 4 cells compared with day 6 cells at the same time.

The accumulation of $\mathrm{PGE}_{2}$ in the medium for control cells is presented (Fig. 4). Analysis of variance of the log-transformed data from control and indomethacin-treated cells indicated a highly significant $(P<0.001)$ three-way interaction between the effects of day, time in culture, and treatment. For cells cultured in the presence of indomethacin, $\mathrm{PGE}_{2}$ concentrations were barely detectable (geometric mean of $98 \mathrm{pg}$ per well) and did not differ between days or times in culture. Under control conditions, $\mathrm{PGE}_{2}$ accumulation increased with time for cells from each day of pseudopregnancy. At 24,48 and $72 \mathrm{~h}$ in culture, $\mathrm{PGE}_{2}$ accumulation by day 5 cells was greater $(P<0.01)$ than for day 4 or day 6 cells. At $48 \mathrm{~h}$ in culture, day 4 cells accumulated more $\mathrm{PGE}_{2}$ than did day 6 cells, but this was reversed at $72 \mathrm{~h}$.

\section{Oestradiol-induced changes in uterine sensitization and decidualization in vitro}

Endometrial stromal cells from uteri exposed in vivo to different amounts of oestradiol were cultured in a series of repeated experiments, and the effects of manipulating $\mathrm{PGE}_{2}$ concentrations on total ALP activity and ALP concentration determined. For total ALP activity (Fig. 5a), analysis of variance indicated a significant $(P<0.01)$ three-way interaction between the effects of oestradiol, time in culture, and treatment during culture. For control cultures, total ALP activity increased significantly $(P<0.001)$ from $24 \mathrm{~h}$ to $72 \mathrm{~h}$, irrespective of oestradiol treatment in vivo. However, total ALP activity at each time, and the increase from 24 to $72 \mathrm{~h}$, was greatest for cells exposed to the intermediate dose of oestradiol.

When indomethacin was present, total ALP activity increased $(P<0.001)$ with time in culture. For cells from animals receiving the high dose of oestradiol, maximal activity was observed at $48 \mathrm{~h}$, whereas maximal activity was found at $72 \mathrm{~h}$ for the other cells. At 48 and $72 \mathrm{~h}$, ALP activity was greater for the intermediate oestradiol cells than for the low or high oestradiol cells. Compared with their respective controls, indomethacin treatment decreased ALP activity at $48 \mathrm{~h}$ and $72 \mathrm{~h}$ for the intermediate dose of oestradiol, and at $72 \mathrm{~h}$ for the high dose.

When $\mathrm{PGE}_{2}$ plus indomethacin were added to the medium, total ALP activity was increased $(P<0.01)$ above that of respective control or indomethacin-treated cells at each time. The ALP activity was greatest $(P<0.01)$ at each time for cells obtained from animals treated with the intermediate dose of oestradiol. ALP concentrations (Fig. 5b) were also analysed to allow for possible treatment effects on the protein content of cultured cells. Analysis of variance revealed a significant $(P<0.05)$ three-way interaction between the effects of dose of oestradiol, time in culture, and treatment during culture. For control cultures, the time-courses of ALP concentrations differed depending on prior treatment with oestradiol. In all cases, ALP concentrations were greater $(P<0.001)$ at $72 \mathrm{~h}$ than at $24 \mathrm{~h}$. For low-oestrogen treatment, ALP concentration did not change between 24 and $48 \mathrm{~h}$, whereas for the other oestrogen treatments there was an increase. The increase in ALP concentrations during culture was greatest for cells of the intermediate oestradiol group. In addition, at $48 \mathrm{~h}$ and $72 \mathrm{~h}$ in culture, ALP concentrations were higher $(P<0.01)$ for intermediate oestradiol cells than for low and high oestradiol cells.

The effect of indomethacin on ALP concentrations varied, depending on treatment in vivo with oestradiol. For low and high oestradiol cells, indomethacin had no significant effect compared with the respective control cultures, except at $72 \mathrm{~h}$ for the high-oestradiol cells in which ALP concentrations were significantly $(P<0.01)$ lower. For the intermediateoestradiol cells, treatment with indomethacin significantly $(P<0.01)$ decreased ALP concentrations at $48 \mathrm{~h}$ and $72 \mathrm{~h}$, but not at $24 \mathrm{~h}$. 

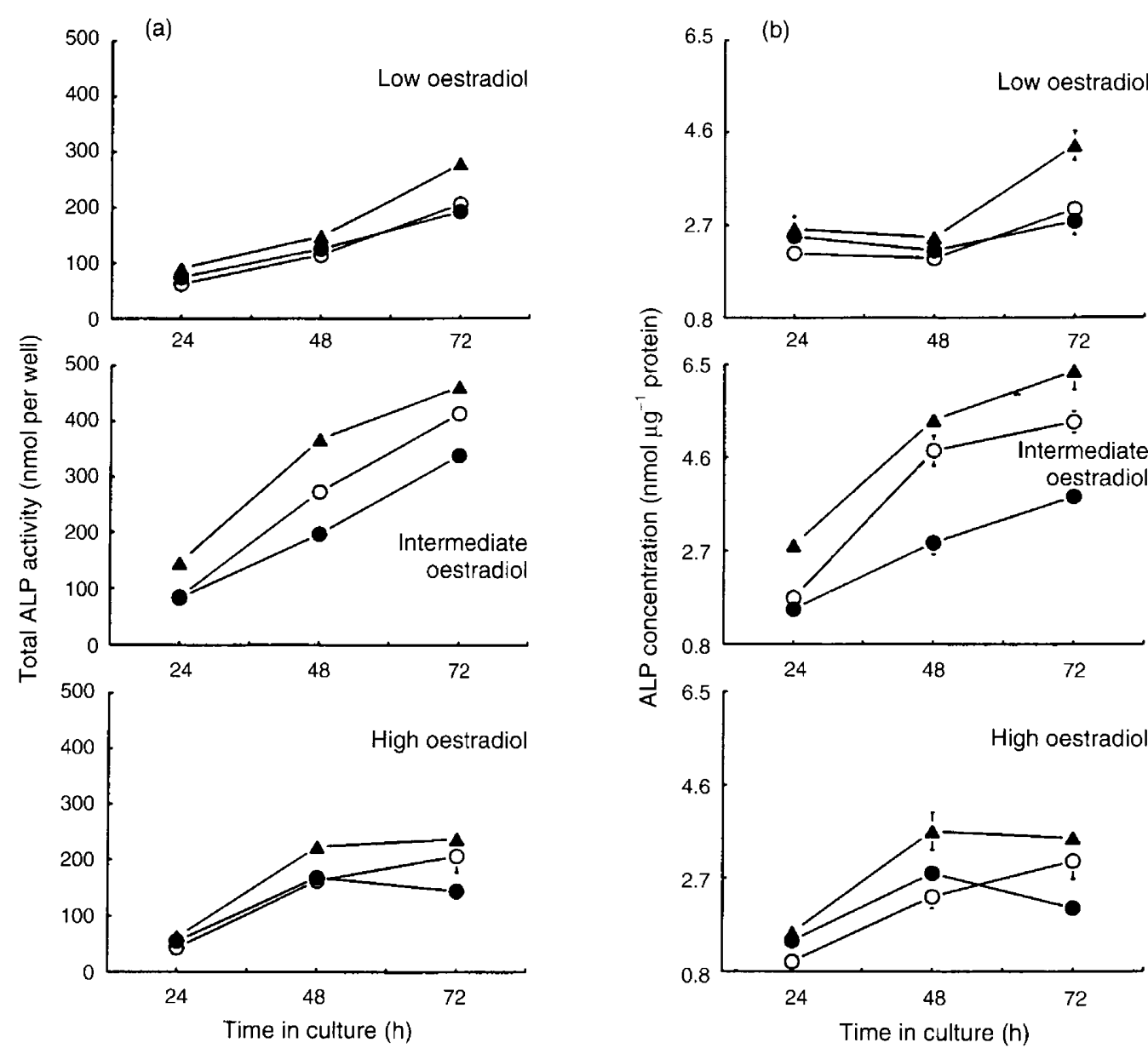

Fig. 5. Total alkaline phosphatase (ALP) activity (a) and ALP concentration (b) in endometrial stromal cells obtained on day 5 from the uteri of rats treated on day 4 with low, intermediate or high doses of oestradiol. The cells were cultured for 24,48 or $72 \mathrm{~h}$ under control $(O)$ conditions, with indomethacin $(1)\left(10^{-5} \mathrm{~mol} \mathrm{I}^{-1}\right)$, or with prostaglandin $\mathrm{E}_{2}(\Delta)\left(\mathrm{PGE}_{2} ; 1 \mathrm{mg} \mathrm{ml}^{-1}\right)$ plus indomethacin. Each point represents the mean \pm sEM of 3-4 observations; where the SEM is not apparent, it is smaller than the symbol.

The effect on ALP concentrations of $\mathrm{PGE}_{2}$ plus indomethacin varied, depending on oestradiol treatment in vivo and time in culture. For intermediate-oestradiol cells, the addition of $\mathrm{PGE}_{2}$ along with indomethacin resulted in ALP concentrations higher $(P<0.01)$ than those found in control or indomethacin-treated cultures at the equivalent time. By contrast, for low-oestradiol cells, the combined treatment had an effect only at $72 \mathrm{~h}$ when ALP concentrations were higher than those of control and indomethacin-treated cultures. For highoestradiol cells, $\mathrm{PGE}_{2}$ plus indomethacin resulted in higher $(P<0.05)$ ALP concentrations at $48 \mathrm{~h}$ compared with the other treatments, but at $72 \mathrm{~h}$ the concentrations did not differ from the controis.

The accumulation of $\mathrm{PGE}_{2}$ in the medium for cells cultured under control conditions is shown (Fig. 6). Analysis of variance of the log-transformed data from control and indomethacintreated cells revealed a highly significant $(P<0.001)$ three-way interaction between the effects of dose of oestradiol, time in culture, and treatment during culture. For cells cultured with indomethacin, $\mathrm{PGE}_{2}$ concentrations were barely detectable (geometric mean of $97 \mathrm{pg}$ per well), and were not affected



Fig. 6. Accumulation of prostaglandin $\mathrm{E}_{2}\left(\mathrm{PGE}_{2}\right)$ in the medium of endometrial stromal cells obtained on day 5 from the uteri of rats treated on day 4 with low $(O)$, intermediate $(\square)$ or high $(\triangle)$ doses of oestradiol. The cells were cultured for 24,48 or $72 \mathrm{~h}$ under control conditions, and the medium was replaced every $24 \mathrm{~h}$. Each point represents the mean \pm SEM of 3-4 observations; where the SEM is not apparent, it is smaller than the symbol. 
$(P>0.05)$ by oestradiol treatment or time in culture. For control cultures, $P G E_{2}$ accumulation increased $(P<0.01)$ for each of the oestradiol treatments from $24 \mathrm{~h}$ to $48 \mathrm{~h}$, and then again from $48 \mathrm{~h}$ to $72 \mathrm{~h}$ except for intermediate oestradiol cells for which there was no difference in accumulation between $48 \mathrm{~h}$ and $72 \mathrm{~h}$. At each time $\mathrm{PGE}_{2}$ accumulation was greatest for intermediate oestradiol cells, and least for low oestradiol cells, except at $24 \mathrm{~h}$ when accumulations did not differ for intermediate and high oestradiol cells, but were greater than for low oestradiol cells.

\section{Discussion}

As indicated by uterine mass 5 days after the administration of a standardized deciduogenic stimulus, the steroid hormone protocols used in the present study produced uteri that were differentially sensitized for the decidual cell reaction. Because the protocois differed only in the hormonal treatment of the animals before the application of the stimulus, the differences in decidualization were a consequence of differential sensitization at the time of stimulation, rather than a consequence of differences in the ability of the treatments to support the process of decidualization. The greatest decidualization was obtained when rats received an intermediate amount of oestradiol $(0.3 \mu \mathrm{g})$ on the equivalent of day 4 of pseudopregnancy, and were given the deciduogenic stimulus on day 5 . Application of the stimulus at earlier (on day 4) or later times (on day 6), or the administration of low (zero) or high $(1.0 \mu \mathrm{g})$ doses of oestradiol on day 4 resulted in substantially reduced decidualization. These results were expected because of the earlier work in rats on the timing of uterine sensitization (De Feo, 1963; Kennedy, 1980a) and the biphasic influence of oestrogen (Yochim and De Feo, 1963; Armstrong and King, 1971; Sartor et al., 1978; Kennedy, 1980b). In addition, using the same protocols as used in the present study, Hamilton and Kennedy $(1993,1994)$ have shown that early responses of the uterus to deciduogenic stimulation - the increases in uterine extracellular fluid volume and vascular permeability - are greatest in rats receiving the intermediate dose of oestradiol and stimulated on day 5 .

In the present study, ALP activity of the cultured endometrial stromal cells was used as an indicator of decidualization. Because the proliferative and growth responses of the cells may have differed, both total ALP activity per well and ALP concentration (activity per unit protein) were measured. The overall interpretation of the results did not differ between the two indicators. For cells from the maximally sensitized uteri (day 5, intermediate oestradiol), there was an increase in total ALP activity as well as ALP concentration with time in culture, the latter observation being in agreement with an earlier study (Yee and Kennedy, 1991). While endometrial stromal cells from less sensitized uteri had increased ALP activities and concentrations with time in culture, the activities and concentrations were always less than those for the maximally sensitized cells. This finding suggests that, as in vivo, the ability of endometrial stromal cells to undergo decidualization in vitro is dependent on uterine sensitization which is time- and hormone-dependent. This conclusion differs from that of Mani et al. (1992) who, based on the expression of desmin and laminin, concluded that decidualization in vitro is independent of uterine sensitization. However, that study was qualitative rather than quantitative, and no comparison of the timecourses for the expression of the markers in sensitized and nonsensitized cells was given.

Decidualization in vivo is mediated, at least in part, by PGs, particularly of the E-series, which are involved not only in the early vascular responses but throughout the process (Kennedy, 1994). Yee and Kennedy (1991) have reported that decidualization in vitro of endometrial stromal cells from sensitized uteri is also mediated in part by $\mathrm{PGE}_{2}$, as assessed by ALP activity. In support of this, the present study shows that indomethacin, at a concentration that reduced $\mathrm{PGE}_{2}$ accumulation in the medium to concentrations that were barely detectable, significantly reduced ALP activity and concentration in sensitized cells. Consequently the observed differences in the ability of differentially sensitized cells to undergo decidualization in vitro may be related to their ability to produce PGs. Two observations in the present study support this hypothesis. First $\mathrm{PGE}_{2}$ accumulation in the culture medium was greatest for the maximally sensitized cells. Second, indomethacin, which inhibited endogenous PG production, had a greater effect on ALP activities and concentrations in the maximally sensitized cells, indicating that the increases had a greater dependency on endogenous PG production. However, when endogenous $\mathrm{PGE}_{2}$ was added to the cultured cells along with indomethacin, ALP activities and concentrations in the cells from nonsensitized uteri were not increased to the values seen in the maximally sensitized cells. If differences in $\mathrm{PGE}_{2}$ production were the sole explanation for the variation in decidualization in vitro, then the exogenous $\mathrm{PGE}_{2}$ should have produced a similar extent of decidualization, irrespective of the state of sensitization of the uteri from which the stromal cells were obtained. These results are analogous to findings in vivo in which it was shown that exogenous $\mathrm{PGE}_{2}$ could not produce endometrial vascular permeability responses (Kennedy, $1980 a, b)$ or decidualization (Kennedy, 1986) in temporally or hormonally nonsensitized uteri equivalent to those obtained in sensitized uteri.

It is not known why endometrial stromal cells from nonsensitized uteri are less able to undergo decidualization in vitro, but it cannot be explained completely by differences in $\mathrm{PGE}_{2}$ production. There are many possible reasons. The nonsensitized cells may have fewer functional PGE receptors; endometrial PGE binding sites in rats are time- and hormonedependent (Kennedy et al., 1983a, b). There may be a deficit downstream from the interaction of $\mathrm{PGE}_{2}$ with its receptors in nonsensitized cells. There is evidence that cAMP is, at least in part, a second messenger for $\mathrm{PGE}_{2}$ in sensitized endometrial stromal cells (Yee and Kennedy, 1991, 1993). Whether analogues of cAMP can override the differential responses to the nonsensitized cells has yet to be determined. Alternatively, the sensitized endometrial stromal cells may produce a mediator that is not produced by nonsensitized cells, which acts together with $\mathrm{PGE}_{2}$ to differentiate the cells. This possibility could be addressed by using media conditioned by sensitized cells.

This work was supported by the Medical Research Council of Canada, Grant MT-10414. 


\section{References}

Armstrong DT and King ER (1971) Uterine progesterone metabolism and progestational response: effects of estrogens and prolactin Endocrinology $\mathbf{8 9}$ 191-197

De Feo VJ (1963) Determination of the sensitive period for the induction of deciduomata in the rat by different inducing procedures Endocrinology $\mathbf{7 3}$ 488-497

Finn CA and Keen PM (1963) The induction of deciduomata in the rat Journal of Embryology and Experimental Morphology 11 673-682

Finn CA and Porter DG (1975) The Uterus pp 93-95 Publishing Sciences Group, Inc, Acton MA

Glasser SR and Julian J (1986) Intermediate filament protein as a marker of uterine stromal cell decidualization Biology of Reproduction 35 463-474

Hamilton GS and Kennedy TG (1993) Uterine extracellular fluid volume and blood flow after artificial stimulation to rats differentially sensitized for the decidual cell reaction Biology of Reproduction 48 910-915

Hamilton GS and Kennedy TG (1994) Uterine vascular permeability after uterine stimulation to rats differentially sensitized for the decidual cell reaction Canadian Journal of Physiology and Pharmacology 72 711-715

Kennedy TG (1979) Prostaglandins and increased endometrial vascular permeability resulting from the application of an artificial stimulus to the uterus of the rat sensitized for the decidual cell reaction Biology of Reproduction 20 $560-566$

Kennedy TG (1980a) Timing of uterine sensitivity for the decidual cell reaction role of prostaglandins Biology of Reproduction 22 519-525

Kennedy TG (1980b) Estrogen and uterine sensitization for the decidual cell reaction: role of prostaglandins Biology of Reproduction 23 955-962

Kennedy TG (1986) Intrauterine infusion of prostaglandins and decidualization in rats with uteri differentially sensitized for the decidual cell reaction Biology of Reproduction 34 327-335

Kennedy TG (1994) Involvement of local mediators in blastocyst implantation. In Endocrinology of Embryo-Endometrium Interactions pp 183-194 Eds SR Glasser, J Mulholland and A Psychoyos. Plenum Press, New York

Kennedy TG, Martel D and Psychoyos A (1983a) Endometrial prostaglandin $E_{2}$ binding: characterization in rats sensitized for the decidual cell reaction and changes during pseudopregnancy Biology of Reproduction 29 556-564

Kennedy TG, Martel D and Psychoyos A (1983b) Endometrial prostaglandin $\mathrm{E}_{2}$ binding during the estrous cycle and its hormonal control in ovariectomized rats Biology of Reproduction $29565-571$
Lowry OH (1957) Micromethods for the assay of enzymes Methods in Enzymology 4 371-372

Lowry OH, Rosebrough NJ, Farr AL and Randall RJ (1951) Protein measurement with the folin phenol reagent Journal of Biological Chemistry 193 265-275

McCormack SA and Glasser SR (1980) Differential responses of individual uterine cell types from immature rats treated with estradiol Endocrinology 106 1634-1649

Mani SK, Julian J, Lampelo S and Glasser SR (1992) Initiation and maintenance of in vitro decidualization are independent of hormonal sensitization Biology of Reproduction 47 785-799

Psychoyos A (1973) Endocrine control of egg implantation. In Handbook of Physiology Vol. II, part 2 pp 187-215 Eds RO Greep, EG Astwood and SR Geiger. American Physiological Society, Washington DC

Sananès N, Weiller S, Baulieu EE and Le Goascogne C (1978) In vitro decidualization of rat endometrial cells Endocrinology 103 86-95

Sananès N, Weiller S, Baulieu EE and Le Goascogne C (1980) Decidualization in vitro. Effects of progesterone and indomethacin Progress in Reproductive Biology 7 125-134

Sartor P, Dupont H, Dupont MA, Deluc AJ and Mayer G (1978) The action of high doses of oestradiol on implantation and decidualization in the rat Animal Reproduction Science 1 93-96

Snedecor GW (1956) Statistical Methods (5th Edn) pp 285-289 Iowa State University Press, Ames IA

Steel RGD and Torrie JH (1960) Principles and Procedures in Statistics pp 107-109 McGraw Hill, New York

Vane IR (1971) Inhibition of prostaglandin synthesis as a mechanism of action of aspirin-like drugs Nature (New Biology) 231 232-235

Vladimirsky F, Chen L, Amsterdam A, Zor U and Lindner HR (1977) Differentiation of decidual cells in cultures of rat endometrium Journal of Reproduction and Fertility 49 61-68

Yee GM and Kennedy TG (1991) Role of cyclic adenosine 3',5'-monophosphate in mediating the effect of prostaglandin $\mathrm{E}_{2}$ on decidualization in vitro. Biology of Reproduction 45 163-171

Yee GM and Kennedy TG (1993) Prostaglandin $E_{2}$, cAMP and cAMPdependent protein kinase isozymes during decidualization of rat endometrial stromal cell in vitro. Prostaglandins 46 117-138

Yochim JM and De Feo VJ (1963) Hormonal control of the onset, magnitude and duration of uterine sensitivity in the rat by steroid hormones of the ovary Endocrinology 72 317-326 